\title{
A novel point for warfarin usage in ACCP Guidelines, 2012 and its importance for quality of anticoagulation. Commentary on the article by Dr. Ciurus et al. (Kardiochir Torakochir Pol 2015; 12 (4): 334-340)
}

\author{
Fahri Gurkan Yesil ${ }^{1}$, Mustafa Kurkluoglu², Adem Guler ${ }^{3}$, Mehmet Ali Sahin $^{3}$, Bilgehan Savas $\mathrm{Oz}^{3}$ \\ ${ }^{1}$ Department of Cardiovascular Surgery, Etimesgut Military Hospital, Ankara, Turkey \\ 2Department of Pediatric Cardiovascular Surgery, Gulhane Medical Academy, Ankara, Turkey \\ ${ }^{3}$ Department of Cardiovascular Surgery. Gulhane Medical Academy, Ankara, Turkey \\ Kardiochirurgia i Torakochirurgia Polska 2016; 13 (2): 192-193
}

We have read with great interest the article about the factors affecting the quality of anticoagulation with warfarin by Ciurus et al. [1]. The authors implicate the importance of predictors of controlling the anticoagulation. They aim to assess the quality of anticoagulant therapy in patients on warfarin and evaluate the factors affecting its deterioration. We thank the authors for their well-designed study. Regarding the current guidelines concerning anticoagulant therapy, we detected some contradictory and overlooked points that should be highlighted. We want to make some contributions to the report by Ciurus et al. [1] about the warfarin usage introduction update and education change according to current guidelines.

Despite the presentation of new anticoagulants, vitamin $\mathrm{K}$ antagonists (VKA) still maintain their importance in clinical administration [2]. Unfortunately, this wide use of VKA is still associated with a wide spectrum of complications. Particular concerns have been raised regarding prevention of these complications. As one of them, the Ciurus et al. emphasized that maximizing the time in the optimum therapeutic range has great importance for avoiding adverse clinical outcomes [1]. To attain this goal, controlling the patient-specific factors such as adherence to the therapeutic plan, appropriate dosing, and reliable international normalized ratio (INR) control are very important. Among such patient-related factors, the feeding habit of the patients is a special issue. Many doctors and patients remember the wide VKA interaction food list containing dietary vitamin $\mathrm{K}$. It has been a frequent practice to limit or alter dietary habits of the patients according to those food lists. But this clinical advice has been changed by the American
College of Chest Physicians (ACCP) Evidence-Based Clinical Practice Guidelines, 2012 [3].

It is suggested in the abovementioned document that limitations of diet deteriorate the therapeutic INR levels. Because most people have long-lasting dietary habits, which are very difficult to change, attempts to change any dietary habit may result in uncontrolled alterations of oral vitamin $K$ intake, resulting in difficulties sustaining the therapeutic INR levels. The ACCP guidelines recommend that "A consistent intake of vitamin K-containing foods is advisable, but neither specific restrictions nor additions seem necessary in patients with stable anticoagulant control. Patients should be informed of possible changes in INR, in particular in response to the use of dietary supplements or herbs, or alcohol used chronically or ingested in large quantities."

The authors reported that, "The participants were informed about the diet limitations required in order to improve the effectiveness of the anticoagulant therapy." Although this suggestion is valid for attaining a therapeutic level, it is very difficult to maintain this level in therapeutic doses. That is why we think the ACCP guidelines made a modification on warfarin use in 2012, which we cannot see in the previous guidelines from 2008 [4]. We also agree with the suggestion that the patient should be informed about the food and drug interactions but no suggestion should be made on limiting dietary intake, in order to maintain therapeutic INR levels.

\section{Disclosure}

Authors report no conflict of interest. 


\section{References}

1. Ciurus T, Cichocka-Radwan A, Lelonek M. Factors affecting the quality of anticoagulation with warfarin: experience of one cardiac centre. Kardiochir Torakochir Pol 2015; 12: 334-340.

2. Ciurus T, Sobczak S, Lelonek M. Truly low and high thromboembolic risk - impact of risk scores in real life. Kardiochir Torakochir Pol 2014; 11: 1-6.

3. Ageno W, Gallus AS, Wittkowsky A, Crowther M, Hylek EM, Palareti G; American College of Chest Physicians. Oral anticoagulant therapy: antithrombotic therapy and prevention of thrombosis. 9th ed. American College of Chest Physicians Evidence-Based Clinical Practice Guidelines. Chest 2012; 141 (2 Suppl.): e44S-88S.

4. Hirsh J, Guyatt G, Albers GW, Harrington R, Schünemann HJ, American College of Chest Physicians. Executive summary: American College of Chest Physicians Evidence-Based Clinical Practice Guidelines (8th Edition). Chest 2008; 133 (6 Suppl.): 71S-109S. 